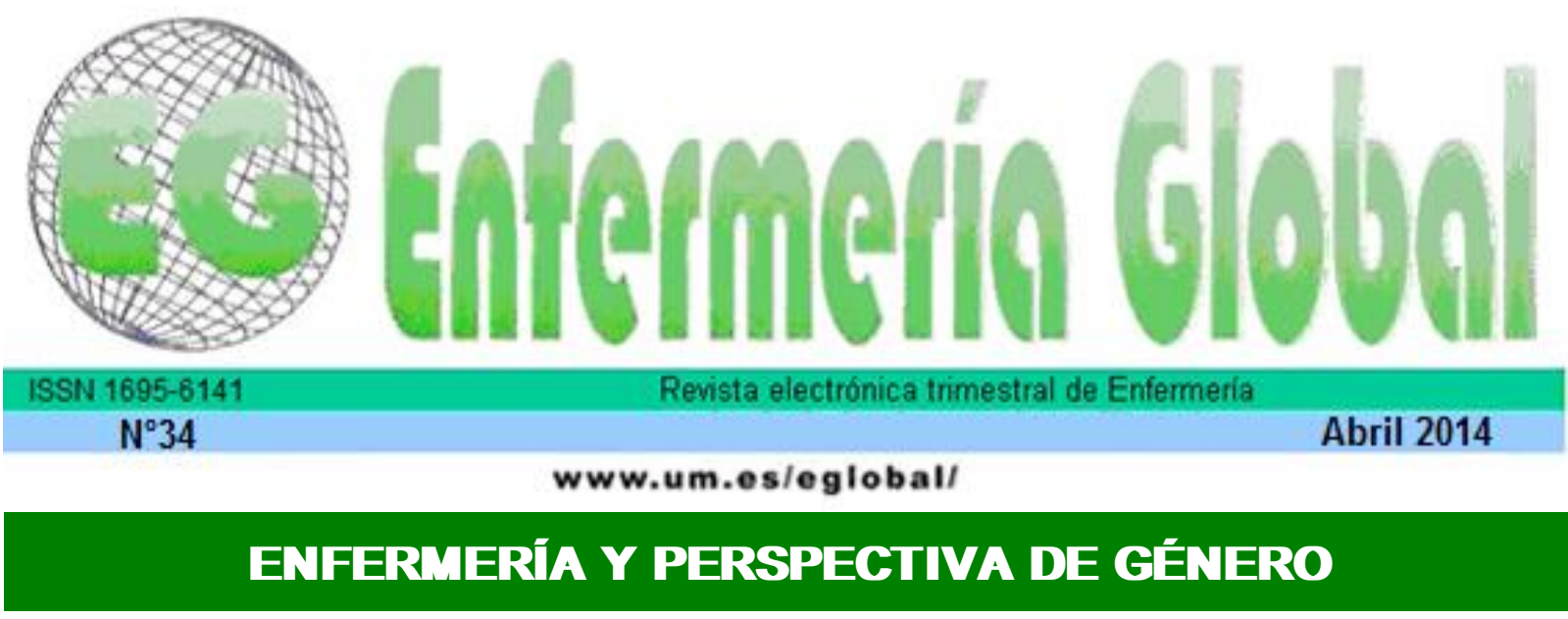

\title{
Entre el deseo, el derecho y el miedo a ser madre tras seropositividad del HIV
}

Entre o desejo, direito e medo de ser mãe após soropositividade para o HIV

Between desire, duty and fear of being a mother after HIV seropositivity

\section{*Liégio Matão, Maria Eliane *Borges de Miranda, Denismar ***Freitas, Maria Imaculada de Fátima}

\begin{abstract}
*Doctora en Psicología. Máster en Enfermería. Especialista en Obstetricia. Profesora Asistente II del Departamento de Enfermería de la Pontifícia Universidad Católica de Goiás/PUC-Goiás E-mail: liegio@ih.com.br ** Máster em Salud, Ambiente y Trabajo. Especialista en Enfermería en Neonatología y Pediatría por la PUC-Goiás *** Doctora en Ciencias de la Educación. Enfermera. Profesora Asociada II de la Universidad Federal de Minas Gerais. Brasil.
\end{abstract}

\begin{abstract}
Palabras clave: seropositividad VIH, la psicología social, el embarazo, los sentimientos Palavras-chave: soropositividade para HIV; psicologia social; gravidez; sentimentos Keywords: HIV seropositivity; social psychology, pregnancy, feelings.
\end{abstract}

\section{RESUMEN}

Objetivo: Comprender las representaciones sociales de las mujeres que conocen su condición de VIH positivo en relación con la maternidad.

Método: Estudio exploratorio, descriptivo, con abordaje cualitativo. Utilizamos formulario socioeconómico y entrevista abierta en profundidad para la recolección de datos y análisis de contenido para establecer categorías temáticas. El estudio fue aprobado por el Comité de Ética de la Universidad Federal de Minas Gerais (057/03).

Resultados: El material fue clasificado y agrupado en tres categorías temáticas: la primera, "El deseo", la segunda "El derecho", y el último, "El miedo".

Conclusiones: El período de gestación está marcado por sentimientos ambivalentes de felicidad, debido a la alegría única de la maternidad, y por el miedo, debido a la posibilidad de transmisión vertical. Se podría decir que el significado del embarazo para estas mujeres gira en torno a los elementos relacionados con el deseo, el derecho y las representaciones sociales sobre el embarazo y el SIDA. 


\section{RESUMO}

Objetivo: conhecer as representações sociais de mulheres conhecedores de seu status positivo para o HIV em relação a maternidade.

Método: estudo exploratório, descritivo com abordagem qualitativa. Utilizou-se formulário sócio econômico e entrevista aberta em profundidade para a coleta de dados e análise de conteúdo para estabelecimento de categorias temáticas. O estudo foi aprovado pelo Comitê de Ética em Pesquisa da Universidade Federal de Minas Gerais (057/03).

Resultados: o material foi classificado e agrupado em três categorias temáticas: a primeira, "O Desejo"; a segundo, "O Direito" e a última, "O Medo".

Conclusões: $O$ período gestacional é marcado por sentimentos ambivalentes de felicidade, por se configurar na alegria ímpar da maternidade, e medo, em razão da possibilidade da transmissão vertical. Pode-se dizer que o significado da gestação, para estas mulheres, gira em torno de elementos referentes ao desejo, ao direito e às representações sociais sobre a gravidez e a Aids.

\section{ABSTRACT}

Objective: to understand the social representations of women who know their HIV positive status in relation to motherhood.

Method: exploratory, descriptive study with a qualitative approach. We used socioeconomic and form open at depth interview for data collection and content analysis to establish thematic categories. The study was approved by the Ethics Committee of the Universidade Federal de Minas Gerais (057/03).

Results: the material was classified and grouped into three thematic categories: the first, "The Desire", the second "The Law" and the last, "The Fear".

Conclusions: the gestational period is marked by ambivalent feelings of happiness, is set in the unique joy of motherhood, and fear, because of the possibility of vertical transmission. You could say that the meaning of pregnancy for these women, revolves around elements related to the desire, and the right to social representations about pregnancy and AIDS.

\section{INTRODUCCIÓN}

En los últimos años, la infección por el VIH ha afectado sobre todo a mujeres en edad que coincide con su período reproductivo - entre 15 y 49 años - es decir, la edad fértil. Los datos también muestran un aumento en los casos de infección entre las mujeres con pareja estable, y la realización del deseo de ser madre por una mujer infectada por el VIH ocurre con relativa frecuencia en la actualidad, en todo el mundo ${ }^{1}$.

Las implicaciones del fenómeno del embarazo en mujeres seropositivas deben ser consideradas en varios aspectos, uno de ellos está relacionado con la tasa de transmisión materno-fetal, que va de $25 \%$ a $35 \%$ de los casos en los que no se ha adoptado ninguna medida profiláctica. Esta tasa se reduce por debajo del $3 \%$ cuando se establecen medidas específicas de prevención durante el embarazo y el parto, como el uso de medicamentos antirretrovirales (ARV), el uso de césarea como vía del parto cuando la carga viral se desconoce o superior a mil copias virales y cuando hay ocurrencia de rotura de membranas para 4 horas $^{2}$. En todos los casos, se incluye la atención adecuada durante el embarazo y el parto, así como la inhibición de la lactancia en las mujeres después del parto y ofreciendo fórmulas infantiles con leche en polvo para el bebé ${ }^{2,3}$. Cabe destacar también los avances en materia de derechos 
humanos, tratando de garantizar el respeto de los ciudadanos a los que viven con $\mathrm{HIV}^{4}$.

El embarazo y la maternidad reflejan las expectativas sociales y culturales muy amplias y surgen en la vida social, la salud relacionada con la vida, la felicidad, la continuidad de la vida, la familia y la especie ${ }^{5}$. Siempre lleva un proceso de introspección y preocupación por la formación de un niño sano. SIDA, por el contrario, surge en el imaginario social vinculado a la muerte, el final de la vida, la desesperanza, la tristeza, el dolor y el sufrimiento ${ }^{6}$.

Toda mujer tiene derecho a quedarse embarazada. La mujer con VIH debe, sin embargo, informarse sobre el mejor momento para quedar embarazada, los problemas más comunes relacionados con las condiciones de asistencia, los medicamentos y las formas de tratamiento, así como la posibilidad de que su hijo nazca infectado o no .

No hay unanimidad sobre este derecho en la sociedad. La pareja en sí se siente insegura; familias, amigos y gente alrededor, juzgan el embarazo como un problema, desaconsejándolo. Este comportamiento se debe probablemente a la falta de avances científicos ya alcanzados, los prejuicios, el miedo a la muerte, entre muchos otros factores. Además de estos, casi por unanimidad, los profesionales de la salud, a pesar de las posibilidades terapéuticas de la protección, tienden a ver negativamente a la mujer embarazada VIH positivas ${ }^{7,8}$.

En oposición a estas representaciones y actitudes, las mujeres conocedoras de su estado positivo de VIH están quedando embarazadas. Sin embargo, este estudio tuvo como objetivo identificar las representaciones sociales de las mujeres que conocen su condición de VIH positivo en relación con la maternidad.

\section{MÉTODO}

Se trata de un enfoque exploratorio, descriptivo y cualitativo, dirigido a las mujeres embarazadas VIH-positivas. Esta alternativa le permite explorar y describir los fenómenos centrados en la percepción, la intuición y la subjetividad de los sujetos, focalizando un universo de significados, motivos, aspiraciones, creencias, valores y actitudes ${ }^{9}$. Formaron parte de este estudio, las mujeres embarazadas en edad.reproductiva.

Se atendieron las disposiciones de la Resolución $196 / 96^{10}$. El estudio se inició después de la aprobación por el Comité de Ética de la Universidad Federal de Minas Gerais - UFMG (aprobación de documentos número 057/03). Se estableció contacto con las mujeres embarazadas infectadas por el VIH durante la consulta prenatal realizada en el ambulatorio de obstetricia de una unidad de referencia en el Estado de Goiás, manteniendo los criterios de inclusión descritos anteriormente, y no hay una negativa a participar.

No hubo un proceso de selección de los sujetos, el criterio de selección fue establecido por el orden de llegada a la misma clínica. La información se obtuvo por medio de la aplicación de dos instrumentos: el primero, forma de presentación de los registros socioeconómicos y segundo, entrevistas abiertas y en profundidad, que se iniciaron con la siguiente pregunta: "Me pregunto señora acerca de su decisión de tener un hijo en este momento". Las entrevistas fueron grabadas y las cintas 
destruidas tras su transcripción literal. El número de participantes no fue definido a priori, siendo la saturación el criterio elegido para el cierre de la recogida de datos.

Se utilizó el análisis de contenido para el establecimiento de categorías temáticas ${ }^{11}$. Se observó adaptación al contenido y al objetivo del estudio para asegurar la homogeneidad (no deben mezclarse s cosas diferentes); exhaustividad-agotamientoagotamiento de la totalidad del texto, exclusividad (un mismo contenido del elemento no se puede clasificar en dos categorías diferentes), la objetividad y pertinencia.

\section{RESULTADOS}

\section{Características sociales, familiares y relacionadas con la infección por VIH}

El estudio incluyó a 13 mujeres embarazadas, todas infectadas por el VIH y conocedoras de su estado serológico. El rango de edad de los participantes es de entre 21 y 34 años de edad, con una media de 26 años. La mayoría de los encuestados (siete) en la capital del estado de Goiás y seis viven en ciudades situadas tierra adentro.

En cuanto a la educación, se formó el grupo, en su mayoría, por mujeres analfabetas, en concreto cinco cursaron enseñanza media completa, cuatro, escuela primaria completa, tres hicieron la primera etapa de la educación básica, y una no posee educación formal alguna conociendo, sin embargo, la lectura y la escritura.

En cuanto a la práctica de una actividad remunerada, ocho de ellos tienen puesto de trabajo, dos sólo funcionan a nivel nacional y tres no se refirieron a esta cuestión. En cuanto a dos declararon que profesan la religión evangélica, las otras no mencionan explícitamente, pero afirman creer en Dios, tener fe y hacer oraciones.

Respecto al estado civil, la mayoría de los encuestados es legalmente soltera (cinco), cuatro están casados, una viuda, dos separadas y una de ellas no hizo ninguna referencia al estado civil. En cuanto a la situación conyugal actual estado civil, las cuatro mujeres casadas viven con sus maridos, otras cuatro personas viven con un compañero, cuatro viven solas, y de estas dos tienen una pareja estable y las otras dos no se relacionan con el padre del bebé. No se pudo explicar la situación de una solamente.

En lo que se refiere a las relaciones sexuales, más precisamente en el número de compañeros a lo largo de la vida, dos se refieren a un solo compañero, diez tenían más de una pareja y una de ellas no hizo referencia al tema. En el momento de la entrevista, dos estaban solas, diez tenían una pareja estable, y una de ellas, hizo caso omiso de dicha información.

En cuanto a los niños, la mayoría de las encuestadas (nueve) tienen hijos. De éstas, tres solo tenían un hijo, cuatro tenían dos, y dos de ellas, tres niños. Dos han experimentado la muerte de un niño, una, al parecer, causada por el SIDA. Cuatro de ellas están embarazadas por primera vez, así que no hay niños en el momento de la entrevista. Entre los nueve participantes que han tenido hijos, la mayoría eran madres adolescentes.

En relación al tiempo que tienen conocimiento de su seropositividad al VIH, la mayoría (diez) tienen esta información durante más de un año y medio, tres lo sabían desde 
menos de seis meses, durante las consultas prenatales. De las diez mujeres conocedores de su estado serológico, se reportaron cuatro respecto a las posibilidades y limitaciones relacionadas con el embarazo y seis de ellas ya habían hablado con su pareja acerca de los niños. Siete embarazos en el uso de medicamentos antirretrovirales.

Al abordar el tema 'uso del preservativo", cuatro declararon su uso en todas las relaciones sexuales, cuatro lo usan a veces, otras dos nunca y una de ellas no se refirió al tema, una informó que su pareja dejó de usar condones después de conocer su estado de $\mathrm{VIH}$ (que es VIH negativo), y, finalmente, una de ellas afirma el uso regular en el inicio de la relación, irregular después y regular tras la confirmación de seropositividad de su pareja.

En cuanto a la pareja actual, siete son seronegativos, cuatro tienen serología positiva del VIH y la serología de dos de ellos no es conocida por las mujeres embarazadas. De los siete compañeros que son VIH-negativos, cuatro usan condones de forma irregular o no lo hacen, aún sabiendo el estado de $\mathrm{VIH}$ de la pareja, y los tres restantes lo hacen de manera regular. En estos casos, la razón de embarazo fue la rotura del condón.

El actual embarazo no fue planificado por la mayoría de las encuestadas (once), sin embargo, tres mostraron en sus discursos alguna forma de planificación, sólo dos de las encuestadas afirman haber planeado el embarazo. De las mujeres que no planificaron el embarazo, tres consideraron la posibilidad de interrumpir el embarazo, una de ellas antes de su confirmación, cuando no conocía el diagnóstico de seropositividad a $\mathrm{VIH}$, dos conocedoras de su estado serológico pensaron la interrupción, una porque no era su deseo tener más hijos y la otra por la presión de sus compañeros y amigos. En los dos últimos casos, esta posibilidad no se ha llevado adelante, una por falta de recursos financieros para que esto ocurra y otra por no haber conseguido ningún servicio para realizar este procedimiento y, por último, que este no es su verdadero deseo. De las 13 mujeres entrevistadas, siete afirman que, de alguna manera, tenía el deseo de tener un hijo y querían el embarazo actual, y seis de ellas fueron explícitas en decir que había un deseo.

Durante las entrevistas, todas las mujeres embarazadas tenian por lo menos 12 semanas de edad gestacional y sólo una de ellas no estaba haciendo uso de los medicamentos antirretrovirales, debido a su edad gestacional (EG) por debajo de la edad recomendada para comenzar.

\section{El análisis fenomenológico}

Después de una lectura minuciosa y sucesiva se obtuvieron todos los materiales, incluyendo lecturas verticales y horizontales, poniendo de relieve los aspectos similares y recurrentes, así como divergente. Por lo tanto, los datos se presentan en tres categorías principales: el deseo, el derecho y el miedo, que se presentan a continuación (Figura 1). 


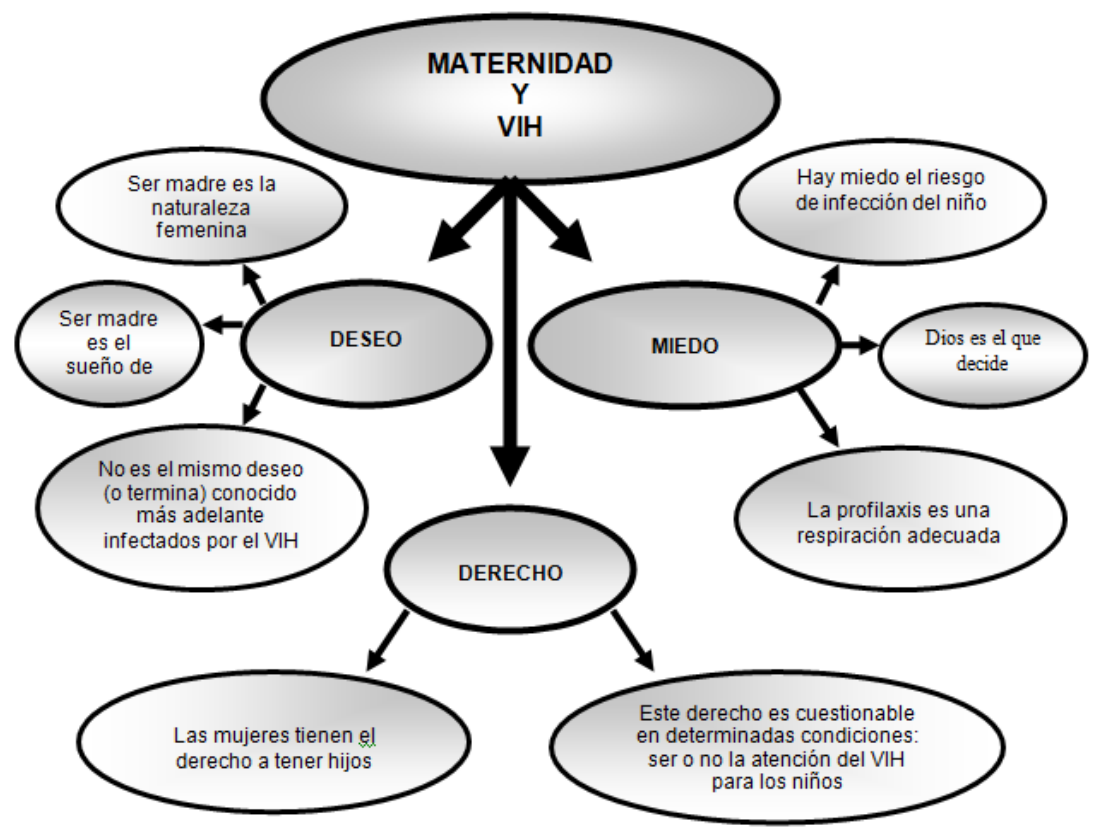

Figura 1: Los núcleos de las representaciones integradoras acerca de la maternidad y de la infección por VIH

\section{Deseo}

El deseo de ser madre es visto como existente en el contexto natural en el que se insertaron antes, es decir, antes de la infección por el VIH, el deseo de ser madre siempre ha existido, en general. A pesar de las similitudes o las diferencias sociales entre los participantes en el estudio, las entrevistadas reportaron haber deseado una vez en su vida la experiencia maternidad. De hecho, ser madre es representado como el gran sueño de cada una, como toda mujer, como se afirma en el discurso siguiente: "Mamá, oye... madre es la mayor felicidad del mundo. Sabiendo que el niño, que la vida vino de dentro de ti "(E3).

A pesar de presentar el embarazo como el deseo natural de cada mujer, sólo unas pocas (cuatro) tuvieron algún tipo de planificación para el embarazo actual, y seis de ellas eran explícitas en la consideración de embarazo prematuro. Después de la infección con el VIH, la representación del deseo normal de tener hijos cambió para la mayoría, como se ve en la siguiente declaración: "Es, pensé, bueno ahora yo no puedo ser madre... sólo que yo dije, no puedo ahora, ¿verdad? yo estoy impedida"(E11).

En cuanto al deseo de tener un hijo en ese momento, una de los participantes admitió que este es el caso, por varias razones, siendo la única que realmente planeó el embarazo, aun conociendo los riesgos y ya tiene dos hijos: "Quedé embarazada y ... porque yo tengo 21 años, ¿verdad? Ya me estoy haciendo vieja [risas] ¿Yo no sé cuándo voy a morir? Así que quiero un hombre joven... No sólo por el deseo de tener un hijo, sino también el deseo de tener uno más, ¿ verdad? Tienen que operar "(E8).

Otra entrevistada dijo haber optado por el embarazo para satisfacer a I compañero que no tiene hijos y es VIH positivo, pero luego revela que no quería el embarazo exactamente en ese momento, debido a las dificultades que está experimentando por haber quedado embarazada luego, sin planificación. 
La mayoría de las encuestadas afirmaron, que no deseaban en este momento el embarazo. Muchas de ellas, por su condición de VIH positivo, algunas por otros motivos, en especial, el nivel socioeconómico de la familia, como se muestra en el siguiente relato: "Yo había decidido que no quería tener hijos. Yo ya tenía uno, pero cuando lo hice, no lo sé todavía, ¿verdad? Que tenía el VIH. Y por eso, a veces, es demasiado doloroso... "(E6).

Sin embargo, algunas de estas mujeres - independientemente de tener o no hijos que se quedó embarazada después del conocimiento de su estado serológico, ya había contemplado como una "broma" la posibilidad de tener hijos o información específica solicitada sobre las posibilidades y limitaciones de un embarazo, especialmente acerca de la transmisión del virus al bebé, o incluso no adoptar medidas anticonceptivas de manera sistemática.

De las que tenían los niños antes, algunas hablan de un deseo de ser madre de nuevo, incluso suponiendo que tienen embarazo programado: "Toda mi vida he querido tener un hijo. Tuve el primero, estaba sin planificación. En la actualidad, de un tiempo para acá luz, yo tenía el deseo de tener otro hijo. En mi mente, siempre he querido tener un niño! Otra niña o un niño. Prefería un chico, pero... "(E2).

De las mujeres entrevistadas del grupo que nunca tuvo hijos, sólo una de ellas expresó no haber quedado embarazada antes, por falta de coraje: "Yo quería ser madre, pero no tenía valor" (E5).

En la trama narrativa de los entrevistados se explicta una "incorporación" / "aceptación" / "certeza del evento" VIH al referirse al evento embarazo en sus vidas, tanto en el deseo de mostrar o no tener un hijo, y este deseo es anulado o se cancela debido a la infección por el VIH en sí.

Es de destacar que la mayoría de las mujeres sabían que estaba infectadas antes de quedar embarazadas (sólo tres mujeres tenían conocimiento de la serología positiva para el VIH durante la atención prenatal y las tres han tenido hijos), pero no tomaron precauciones para que esto no suceda, señalando la existencia de una paradoja en la categoría de deseo: "No deseo nada más [o de la misma manera] tener hijos, no se debe quedar embarazada, pero lo hice"

En la práctica, entonces, la búsqueda del deseo, lo que podría llamarse primaria, fue predominante en relación con el contexto de la infección por el VIH. Sin embargo, las mujeres que conocían su infección por el VIH en el transcurso del embarazo actual -todas madres de hijos vivos- revelaron que si hubiesen conocido la infección no habrían quedado embarazadas o solo se arriesgarían caso de que no hubieran tenido hijos, y después de obtener información sobre las posibilidades de embarazo: "Tengo mucho miedo de que también tienen el virus. Creo que si yo lo supiese yo no lo habría tenido. ;Debido a que es muy arriesgado para los niños que nacen con el virus! "(E2).

Así, se puede decir que para todas las mujeres entrevistadas, la maternidad se presenta como parte de la condición de mujer y una de las principales cosas buenas en tu vida, con una modificación de esta representación cuando se saben VIH positivo. Para muchas, experimentar la maternidad se convierte en la condición de sentirse realizada, por eso la realización del deseo de ser madre "resbala" con la infección por el VIH. El deseo, aunque negado como tal, es experimentado por las 
mujeres, incluyendo aquellas para las que el VIH se presenta como el principal obstáculo de tener hijos. A esta última comprensión, se suma la diferencia que hay entre tener o no las condiciones materiales y económicas para criar a los hijos, que se entrelazan con el derecho a la maternidad.

\section{Derecho}

Las mujeres del estudio que tienen hijos abordaron la cuestión del derecho o no a la maternidad. Sin embargo, el derecho no se menciona - ni siquiera una mirada - por la mayoría de las que no los tienen.

Para algunas, el derecho a la maternidad aparece como una condena, siendo que dos de ellas se centran en la autonomía de las mujeres cuando se refieren a la opción de tener hijos: "Si quieres, ¿verdad? [Ser madre]. Si hay voluntad hay que seguir adelante "(E8)," Oh, creo que cada mujer tiene que ser madre. Supongo. Porque ser madre es muy bueno. A pesar de que la gente igual contaminada así, de todos modos, me siento muy feliz con mi hija "(E2).

Por el contrario, otra entrevistada dice expresamente que, en su opinión, la mujer VIH positiva no debería tener ese derecho. Sin embargo, en otro punto de la narración dice de manera diferente, con un poco de advertencia: "¡Ah! Creo que la mujer que tiene el virus no podía tener un hijo. Si fuera mi voluntad, no lo tendría (E7). Tuvo un error porque, como él pensaba, enfermo "(E7).

Recordemos que para esta entrevistada, el derecho existe, pero es cuestionable para las mujeres infectadas por el VIH. Su embarazo actual fue aceptado en un espíritu de sumisión a la suerte, de haber ocurrido, dijo, debido a la rotura del preservativo, cuando se usa con regularidad por la pareja. E7 estaba muy enojada con su embarazo, lo que puede explicar el conflicto de tener o no el derecho a quedar embarazada cuando se es VIH positivo.

Para las otras dos, tal restricción sería para las mujeres que no toman el cuidado de los hijos: "Mira, yo creo que cada mujer tiene que ser madre. Menos aquella que así... que hablan de ser madre por hablar "(E3)," No, no creo que todas! Porque para tener un niño maltratado... "(E10).

De las mujeres que no tienen hijos, sólo una se refiere al tema diciendo percibir la maternidad como derecho de la mujer, sin embargo, por eso, se privaría de la misma: "Creo que cada mujer tiene que ser una madre así. Creo que es un derecho, ¿no? No lo sé... Yo iba a privarme de ese derecho si el condón no se hubiera roto [debido a que está infectado] "(E5).

Por lo tanto, se puede afirmar que el derecho a la maternidad no es unánime entre los encuestados cuando la mujer está infectada por el $\mathrm{VIH}$, resaltando por ello que la mayoría no recuerda el tema, o por lo menos, no lo centró en sus narraciones.

\section{Miedo}

La posibilidad de que el VIH se transmita al niño es el mayor problema que se percibe y se incorpora por los entrevistados. Aparece como uno de los argumentos más fuertes al justificar no desear un embarazo en el estado en que se encuentran: "Pero entonces, después de que me enteré de que tenía este problema y, a continuación, 
finalmente, bueno, no es que simplemente acabó siempre tuve el deseo! Pero siempre no, una lata, una lata, el niño va a nacer... Va a ser igual que yo... Será más al principio me necesitará, está en las manos de otros, que se puedan hacer cargo? "(E5).

Una de ellas dice claramente que si no hubiese tal riesgo, todo sería diferente: "Bueno, más... Hay momentos en que nos sentimos tristes, eh! ¡Por estar así! ... Este negocio, pasar el virus a él... [Se refiere al bebé] [Entrevistador: si no pasase, no tendría más preocupación] De hecho ninguna. Ni.. "(E7).

Las mujeres ponen muchas esperanzas en la posibilidad de que el niño nazca sin el virus, y para que esto suceda, ellas saben la importancia del tratamiento recomendado. Sin embargo, creo que el resultado final - bebé nacido infectado o no como la voluntad de Dios, que es aprehendido también de frases como: "Pero... es lo que Dios quiere, claro! Si naciera, yo me encargo de la misma manera "(E1)," Estoy pidiendo a Dios, orando también [empuja durante este discurso, que muestra por su manera de rezar las manos] a Dios, él [bebé] nace sin problema, a pesar de lo que soy, ni el padre, ni... Estoy pidiendo a Dios para él que no nazca seropositivo "(E3).

En la estructura del discurso parece que el sufrimiento existe, de manera constante, debido a la posibilidad de infección del bebé, contrapesada por la esperanza de no transmitir el uso correcto de los medicamentos y el poder de la fe en Dios.

\section{DISCUSIÓN}

Los datos empíricos muestran la vida social, familiar y en relación con la infección por $\mathrm{VIH}$ de las mujeres embarazadas, que componen el presente estudio, similar a la de otras mujeres embarazadas VIH positivas de otros países ${ }^{1,12}$ y que no divergen del perfil de la población de las mujeres embarazadas no infectadas por el $\mathrm{VIH}$, edad, educación, trabajo y estado civil $^{13}$.

El grupo de edad está incluido en el período en el que la edad reproductiva se considera ideal. La definición internacional de la mujer de edad reproductiva es de entre 15 y 49 años, en Brasil es entre 10 y 49 años, con las recomendaciones de entre 17 y 35 años para favorecer a menores de los riesgos de la gravidez ${ }^{14}$.

En cuanto a la educación, esta indica, comforme otros estudios ${ }^{6,13}$ y los datos del Ministerio de Salud (MS) ${ }^{1}$, un promedio de años de estudio de no más de ocho, lo que puede permitir la inferencia del empobrecimiento como una característica común de la infección por VIH.

Con independencia de su estado civil legalmente definida, la mayoría vive en sociedad estable y de convivencia con pareja actual, lo que representa también la realidad nacional, como se ve en otros estudios ${ }^{12-13}$. En este sentido, destaca: entre los participantes de este estudio, para la mayoría, el compañero actual no es el primero ni incluso esta es la primera experiencia conyugal, y estos cambios son un comportamiento de riesgo para la infección por el $\mathrm{VIH}$, también encontrada como realidad nacional ${ }^{1}$.

Estas características, sumadas a las otras comunes a las mujeres - subempleo, dependencia económica, sumisión, religión, entre otras- les impiden franca negociación con la pareja, especialmente con respecto al uso de condones. Como se 
ve, es lo que sucede efectivamente en la vida cotidiana de muchos de los entrevistados. La importancia del uso del condón es conocida y valorada en términos conceptuales, pero no se ha adoptado la práctica regular, que se describe de manera similar en los estudios de las personas infectadas o no por $\mathrm{HIV}^{12,15}$, influido por factores culturales, emocionales, económicos, y por las actitudes inadecuadas de conservación y control de la propia salud ${ }^{16}$. Algunas mujeres informaron del uso continuo del condón, lo que no impidió el embarazo. Los estudios presentados por los Estados miembros confirman el alto grado de protección que ofrece el "condón", tanto para la anticoncepción y la prevención de la transmisión de $\mathrm{HIV}^{17}$. Sin embargo, los mismos estudios admiten la posibilidad de permeabilidad (fugas) y el fracaso del condón, incluso en porcentajes muy bajos.

En cuanto al conocimiento de su estado VIH positivo, hay mujeres entre las participantes del estudio que vivieron la experiencia en el transcurso del embarazo, la realidad de muchas mujeres en el país. De acuerdo con el MS, el período de gestación es, para muchas mujeres que no son conscientes de su infección por el VIH, la oportunidad más importante - si no la única - del acceso a servicios de asesoramiento, pruebas y tratamiento del VIH conforme a su condición de salud ${ }^{1-2}$.

Por más que en la contemporaneidad, gracias a los movimientos de liberación de las décadas de 1960 y sus desdoblamientos ${ }^{18-19}$ las posibilidades sociales para las mujeres se han ampliado y diversificado, no han causado el abandono de las representaciones de la maternidad arraigadas en el mito del amor maternal, a pesar de su cuestionamiento en los últimos décadas ${ }^{20}$. Para las mujeres, en especial los miembros del grupo de entrevistados, se menciona el deseo de ser madre casi como calcado de las creencias de la naturalización de la "condición" de la mujer, o sea como algo fundamental vinculado a la mujer, un verdadera atributo femenino ${ }^{5,21}$. Ser madre se representa socialmente como algo fundamental para la mayoría de las mujeres en general, convirtiéndose entonces en el objetivo de su vida para sentirse realizadas y vivas en el mundo. También contribuye a esta condición, la relación entre quedar embarazada y tener salud, que parece ser importante en el contexto de estas mujeres, como una confirmación de la vida. Por lo tanto, aunque la decisión de no tener hijos, pueda estar presente significativamente hoy ser bien aceptados en el ámbito social, con independencia de la cuestión o la motivación - la falta de estabilidad financiera, logros profesionales, la falta de "instinto maternal", entre otros la maternidad está anclada en la idea de la naturalidad, y como tal, en la estructura imaginaria de los grupos sociales acerca de las mujeres, que consta de una estructura real mítica ${ }^{22}$. Y como conciencia mítica, tiene raíces en lo sobrenatural para ciertas clases de explicación como verdad sin ningún requisito de comprobación. Así que, para muchas mujeres, ser madre es cumplir un plan de Dios. A los miembros del grupo de investigación, sobre todo antes de la infección por $\mathrm{VIH}$, el deseo de ser madre es común a todos, algo casi innato, que perciben como siempre presente en sus vidas.

Sin embargo, el conocimiento de seropositividad a $\mathrm{VIH}$, sobre todo debido a la posibilidad de transmisión del virus al niño, es generador de conflictos relacionados con el ejercicio de la maternidad, ya que existe el deseo y permanece presente, no hay ningún cambio en este sentido. Lo que ocurre es su paso al estado "latente", especialmente en los días y meses más próximos al diagnóstico de la infección. Hay una renuncia personal hacia lo que es explícito en la declaración de que "la maternidad no se combina con el VIH", configurado como el argumento central que soporta las narrativas de las mujeres sobre la renuncia a tener un hijo. 
En el presente estudio, independientemente de su estado civil, el embarazo es inicialmente asumido por la mayoría como algo que no se planifica. Sin embargo, algunos en el transcurso de la entrevista, revelan hechos que pueden estar relacionados con una cierta negligencia intencional o "acción inconsciente hacia la cuestión reproductiva de la pareja". Parece que con el paso del tiempo, la vida diaria con el VIH y todas sus consecuencias, tanto personales como sociales, sedimenta sentimientos y pensamientos sobre el nuevo estado serológico, lo que en última instancia, dar de alguna manera un acoatumbrarse a él - el VIH - presente en sus vidas. ¿Qué pasa con el embarazo?, es como si, poco a poco, se estaban preparando para el evento como una manera de no renunciar a un deseo que se representa como algo inherente a la condición femenina, y representa una forma de sentirse vivo.

Muchas mujeres, a pesar de comprender el embarazo como resultado de un comportamiento sexual sin protección o un fallo en el método adoptado por la pareja, terminan creyendo que están sometidas a una fuerza impulsora externa de la persona, en lo que se refiere, específicamente, a la autonomía de la decisión de quedar embarazada. El embarazo es visto, entonces, como algo que tenía que suceder en su vida en ese momento, determinado por una extraña fuerza insondable, un deus ex machina.

Esta justificación se puede atribuir para prevenir, en cierto modo, la crítica e incluso una posible condena social, ya que ellas mismas no pueden ser culpados por un evento, es como si fueran actores que actúan en una escena creada y dirigida por un autor que tiene el control total de lo que debe o no debe suceder. Por lo tanto, "actuar como actriz" es una manera de eximirse o abstenerse de actuar, es decir, lo que pasó en ese momento, debido a esta fuerza mayor, determinante. En este caso, la mujer no ejerce su libre albedrío y por lo tanto puede evadir la responsabilidad de una participación activa (consciente). El sentido común tiende a ser más indulgente en estos casos. Para la mujere, se evitan las sanciones sociales y se reduce al mínimo y el prejuicio social, que puede ser muy fuerte.

La religiosidad, la fe racional en Dios y la sumisión a designos divinos, ya sea como regalo o castigo, permiten también explicar y aceptar o soportar con menos sufrimiento los acontecimientos impuestos a la persona. Las mujeres entrevistadas, en su mayoría, se refiern al embarazo actual como sucedido según el plan de Dios para sus vidas y así, finalmente se rinden, aceptando el hecho y, por tanto, la causa del embarazo, no por razones míticas, sino debido a la creencia de que tienen la presencia divina.

En cuanto a la percepción de la experiencia del embarazo después de seropositividad al VIH como un ejercicio de la ciudadanía, especialmente sus derechos reproductivos, no fue recordado por la mayoría durante los relatos. Por un lado, esta mujer puede no percibirse como digna de derechos debido a un sentimiento de culpa por haber infectado y por lo tanto no experimenta lo mismo que las otras mujeres. La representación de la discriminación social de que son actos pecaminosos que traen el SIDA parece estar directamente relacionada con el derecho a la maternidad, dada la relación entre este hecho y el carácter santificado asignado. También se puede hablar de este tema a la luz del esperado "sentido de protección" de la madre al niño, y, en este caso, la madre estaría exponiendo al bebé directamente al riesgo de infectarse con el VIH. Por otro lado, no centrar literalmente esta temática, puede derivarse del el ejercicio de hacer lo mismo, una vez que están embarazadas. 
Por lo tanto, aunque no fue referido como un derecho para todas ellas, renunciar o abandonar la posibilidad de tener un hijo puede estar basado en principios morales y éticos nobles como la seguridad, la defensa y el respeto de los demás. Sin embargo, la decisión es de ellas, también basada en el principio de que el niño no tiene la culpa $\mathrm{y}$, si se produjo, es necesario "guardarlo" como un regalo, que es también una representación social de la maternidad, en general, que existe en todas las entrevistadas, a pesar del riesgo de transmisión vertical temido por todas (miedo). Ese riesgo fortalece en ellas, de modo intenso, la prohibición de la gestación. Parece que la memoria funciona como una sombra que las acompañara, o como si el virus estuviese como una constante amenaza, que funciona simbólicamente, como un fantasma en sus vidas. Por lo tanto, mantener el embarazo actual es una forma de culpa, que manejan sobrevalorando el evento como un permiso divino.

Estos resultados son consistentes con otros estudios realizados en la última década, en una época en que la profilaxis de la transmisión vertical se define como una política pública que presenta diferentes contornos de la propuesta actual ${ }^{21}$.

\section{CONCLUSIONES}

El análisis de las entrevistas mostró, desde el principio, un gran número de embarazos no deseados, así como la representación de las mujeres en gran medida vinculadas a la maternidad,siendo su ejercicio como una expectativa para la mayoría. La infección por el VIH no modifica sustancialmente la representación de la maternidad y el deseo de tener hijos, a pesar de que es la razón para reducirlos, al menos en teoría, ya que, en este sentido, no hubo adopción de métodos anticonceptivos.

En el grupo entrevistado, las mujeres están en el ideal de la edad reproductiva, algunas no tienen hijos o han encontrado un nuevo compañero, a veces sin hijos, y el deseo por lo tanto legítimo de reunirse y formar una familia. Sin embargo, se sienten inicialmente impedidas de tener hijos debido a la infección por el $\mathrm{VIH}$ al final del embarazo, son felices, pero preocupadas por la posibilidad de transmitir el virus a su hijo. En la mayoría de los casos, informan de la aparición de embarazo como el cumplimiento de una prescripción divina, a quien entregan el resultado final de la serología bebé. Sin embargo, a pesar de ello, se someten a las recomendaciones de la profilaxis para minimizar, al máximo, ese riesgo.

Se puede decir que existe un cierto desconocimiento por parte de las mujeres acerca de sus conocimientos sobre la reproducción como un derecho individual de todas las personas, y cada una conscientemente decidir sobre su propio cuerpo, sin ninguna forma de discriminación y como un ejercicio de la ciudadanía, independientemente de si está o no infectada por el $\mathrm{VIH}$, ya que todas se encuentran en pleno ejercicio del derecho reproductivo. Sin embargo, muchas mujeres que participaron en este estudio experimentaron sentimientos de vergüenza y culpa, motivados por las condiciones del embarazo en que se encuentran.

En la población estudiada, en ningún momento, se hace referencia a la anticoncepción de emergencia como una posible opción para casos de accidentes con el preservativo, sobre todo en los casos de embarazo no deseado. Tampoco hubo ningún acercamiento a la reproducción asistida, especialmente en los casos en que el compañero sea discordante - única oportunidad segura de no transmitir el virus a él a pesar de comprobar la asociación con muchos compañeros seronegativos. 
Cuestión importante a considerar es la alta frecuencia con que el condón ya no se usa en las parejas serodiscordantes, a pesar de las revelaciones explícitas de conocimiento adecuado de la importancia de esta práctica y su reconocimiento como una necesidad esencial.

Lejos de la intención de agotar tema tan amplio, polifacético y complejo, se buscó pensar en un asunto en el caso de la epidemia de $\mathrm{VIH}$ / SIDA especialmente entre las mujeres. Así, desvelar el proceso argumentativo presentado por las mujeres que quedaron embarazadas después del diagnóstico de seroconversión del $\mathrm{VIH}$ o que quedaron embarazadas sin una definición previa de su estado de $\mathrm{VIH}$, pero que asumieron el embarazo es importante para contribuir al fortalecimiento de las discusiones y reclamaciones de los derechos humanos, parte sexual y reproductiva de la población infectada, así como para ayudar en la comprensión de la experiencia del embarazo y, por lo tanto, permitir, de alguna manera, la formulación de políticas públicas con estrategias viables que puedan satisfacer sus necesidades reales .

\section{REFERENCIAS}

1. Brasil. Ministério da Saúde. Secretaria Executiva. Coordenação Nacional de DST e AIDS. Políticas e diretrizes de prevenção das DST/Aids entre mulheres. Brasília: Ministério da Saúde, 2003: 104.

2. Brasil. Ministério da Saúde. Secretaria Executiva. Coordenação Nacional de DST e AIDS. Projeto Nascer. Brasília: Ministério da Saúde, 2003: 80.

3. Van Dyke RB, Korber BT, Popek E, Macken C, Widmayer SM, Bardeguez A, et al. The Ariel Project: a prospective cohort study of maternal-child transmission of human immunodeficiency virus type 1 in the era of maternal antiretroviral therapy. $J$ Infect Dis 1999; 179(2): 319-28.

4. Chequer P. Apresentação. In: Coordenação Nacional de DST e AIDS. HIV nos tribunais. 2. ed. Brasília: Ministério da Saúde, 1999: 7-9.

5. Miranda DB, Bortolon FCS, Matão MEL, Campos PHF. Parto normal e cesária: representações de mulheres que vivenciaram as duas experiências. Rev Eletrônica Enferm 2008; 10(2): 337-46.

6. Paiva MS. Vivenciando a gravidez e experienciando a soropositividade para o HIV. [tese]. São Paulo (SP): Escola de Enfermagem/USP; 2000.

7. Barcellos NT. AIDS, a mulher e a gravidez. Jornal da FEBRASGO 2001; 8:10-1.

8. Matão MEL, Rossi FGP. Representações Sociais da gravidez de mulheres pelo HIV. Revistas Estudos, Vida e Saúde 2001; 28(6): 1073-102.

9. Figueiredo NMA. Método e metodologia na pesquisa científica. São Caetano do Sul: Difusão editora; 2004.

10. Brasil. Ministério da Saúde. Comissão Nacional de Ética e Pesquisa. Conselho Nacional de Saúde. Manual Operacional para Comitês de Ética em Pesquisa. Série CNS - Cadernos Técnicos, série A, Normas e Manuais Técnicos, n. 133. Brasília; 2002: 83-91.

11. Bardin L. Análise de conteúdo. Lisboa: Edições 70, 2002.

12. Villela W. Sobre desejos, direitos e necessidade. In: Brasil. Secretaria de Políticas de Saúde. Coordenação Nacional de DST e AIDS. Cidadãs positHIVas. Brasília: Ministério da Saúde. 2002: 69-97.

13. Barbosa RHS. Mulheres, reprodução e aids: as tramas da ideologia na assistência à saúde de gestantes HIV positivas. [tese]. Rio de Janeiro(RJ): Escola Nacional de Saúde Pública; 2001. 
14. Brasil. Ministério da Saúde. Secretaria de Políticas de Saúde. Coordenação Nacional de DST e AIDS. Vigilância do HIV no Brasil: novas diretrizes. Brasília: Ministério da Saúde, 2002.

15. Araújo MLM, Santos R, Mendes AL, Rodrigues LH, Canella PRB. Saber sobre a importância do uso do preservativo influencia o seu uso? Reprodução \& Climatério 2002; 17(1):25-9.

16. Neves LAS, Gir E. Crenças das mães soropositivas ao HIV acerca da transmissão vertical da doença. Revista Latino-americana de Enfermagem 2006; 14(5): 140-7.

17. Anjos RHD, Silva JAS, Val LF, Rincon LA, Nichiata LYI. Diferenças entre adolescentes do sexo feminino e masculino na vulnerabilidade individual ao HIV. Rev Esc Enferm USP 2012; 46(4): 829-37.

18. Teixeira ETN. Adiamento da maternidade: ser mãe depois dos 35 anos. [dissertação]. Rio de Janeiro (RJ): Escola Nacional de Saúde Pública, 1999.

19. Santos LGS. A percepção da maternidade no processo evolutivo da mulher. [dissertação]. Rio de Janeiro (RJ): Instituto Fernandes Figueira da Fundação Osvaldo Cruz, 1991.

20. Badinter E. Um amor conquistado: o mito do amor materno. São Paulo: Nova Fronteira, 1998.

21. Pereira MLD. Ser mãe e estar com aids: o revivescimento do pecado original. São Paulo: Edusp, 1997.

22. Santos MFS, Novelino AM, Nascimento A P. O mito da maternidade: discurso tradicional sob roupagem modernizante? In: Moreira ASP, Jesuino JC Representações Sociais: teoria e prática. 2. ed. João Pessoa: Universitária, UFPB, 2003: 255-278. 